\title{
Occupational allergy after exposure to caddis flies at a hydroelectric power plant
}

\author{
Allen Kraut, Jeff Sloan, Fanny Silviu-Dan, Zhikeng Peng, Diane Gagnon, \\ Richard Warrington
}

\begin{abstract}
A cross sectional survey was conducted in a hydroelectric power plant in which the workforce was exposed to large numbers of caddis flies. 28 of 57 employees participated. About $50 \%$ of the participants reported work related eye, nose, and sinus symptoms and wheezing. Working in locations with greater exposure to caddis flies was significantly associated with work related symptoms. 17 workers (61\%) were skin prick positive to a laboratory prepared caddis fly antigen (LCFA) made from the remains of caddis flies present in the plant and $11(39 \%)$ had positive reactions to a commercial caddis fly antigen (CCFA). Workers stationed in heavily exposed areas were 3.7 times as likely to have a positive response to the LCFA $(p=0.009)$ and 5.3 times as likely to have a positive response to the CCFA $(p=0.036) .13(46 \%)$ of survey respondents reported three or more work related symptoms. 10 (91\%) CCFA positive workers reported three or more work related symptoms. Pulmonary function studies revealed slight, but not significantly decreased forced vital capacity (FVC), forced expiratory volume in one second $\left(F E V_{1}\right)$, and $F E V_{1} / F V C$ ratios in workers who were skin test positive to either caddis fly preparation when compared with those who were negative. One worker who was skin test positive to both antigens had a cross shift fall in $F E_{1}$ of $20 \%$ predicted. Occupational allergy to caddis flies proved to be a significant health problem at this work site.
\end{abstract}

(Occup Environ Med 1994;51:408-413)

Caddis flies are members of the order Trichoptera (hairy wings). Allergic reactions to these insects were first reported in $1929 .{ }^{1}$ Sensitisation to caddis flies is common in Japan where $53.6 \%(30 / 56)$ of asthmatic patients compared with $8 \cdot 7 \%(2 / 23)$ of nonasthmatic patients had positive intracutaneous skin tests against the caddis fly wing. ${ }^{2}$ The extent of symptoms caused by this sensitisation was not reported. Exposure to caddis flies may lead to symptoms in occupational groups. Kagen et $a l^{\beta}$ reported that $40 \%$ of an exposed workforce had allergic rhinitis or symptoms of asthma aggravated by exposure to caddis flies. We report the investigation of a workforce heavily exposed to caddis flies.
The site of the investigation was a hydroelectric power plant, operated in Manitoba, Canada. The plant first opened in 1911. For some decades, workers in this plant reported exposures to large numbers of caddis flies throughout the summer season. The species of fly identified was Hydropsyche recurvata. The many flies present in the work environment was due to a combination of factors. Firstly, the physical structure provided a permanent habitat, secondly, the high water flow provided an excellent source of nutrition, and finally, the adult flies were attracted by the lights at the station (Flannagan J, personal communication).

Workers at the plant commonly reported symptoms including watery eyes, runny nose, sinus congestion, cough, wheeze, and shortness of breath after exposure to caddis flies. Exposure occurred during the summer when the flies hatched as well as during the winter when dry, dead caddis flies are present in the pumping station. Caddis flies were taken into and pulverised by the turbines and dispersed into the air of the plant. To further evaluate these complaints, the Canadian Union of Public Employees, representatives of the workers at the plant, and the management of the plant requested that the Manitoba Federation of Labour Occupational Health Centre conduct an investigation into this problem. On 12 and 13 August 1991, a survey of the workforce at the pumping station took place. A summer date was chosen as this is part of the caddis fly hatching season.

The plant was a large building, $65 \times 518 \times 46$ feet. Electricity is generated by 18 turbines. Workers generally worked in one of four areas, the office, the control room, other areas of the power plant, and outside the plant. Caddis flies entered the plant when the water moved over the turbines. Exposure was thought to be greatest in the control room, which was not specifically sealed off from the plant and in the remaining areas of the plant outside of the office. Numerous dead caddis flies were noted in light fixtures in the control room. In certain areas of the plant remains of dead caddis flies were a few inches deep. Lower exposures were reported in the office and outdoors.

\section{Materials and methods}

SUBJECTS

All workers at the plant were invited to participate in the survey. Those who agreed were informed of the study protocol and provided 
consent. The investigation consisted of a self administered questionnaire based on the American Thoracic Society's epidemiological questionnaire $^{4}$ along with specific questions for current occupational exposures and allergic symptoms. Workers were asked which of a list of symptoms they experienced more than twice a year. Eye symptoms referred to problems such as tears and watery or red eyes. Nose symptoms referred to problems with stuffy, runny, or dripping nose, and sinus symptoms referred to complaints of sinus congestion or other sinus problems. Wheezing referred to those who reported that their chest ever sounded wheezy or whistling. Workers who reported attacks of shortness of breath were reported to have breathlessness. Work related symptoms were defined as present if workers answered yes to the question, "Does your symptom get better when you are away from work on weekends and vacations?". If workers reported that they did not have a specific symptom or that the symptom did not get better when away from work or on vacation, they were assumed not to have a work related symptom.

\section{SKIN TESTS}

Skin prick tests consisted of a battery of antigens including various local tree, grass, weed, and mould antigens. Testing was also performed with house dust mite antigen, a commercial caddis fly antigen (CCFA) purchased from Hollister-Stier Miles Canada Inc, Etobicoke, Ontario, and a laboratory caddis fly antigen (LCFA) produced from remains of caddis flies collected at the plant. The LCFA was prepared as a $5 \% \mathrm{~W} / \mathrm{V}$ aqueous extract of caddis fly wings filtered before use.

The common inhalants were tested as mixed tree pollens, mixed grasses, mixed weeds, and mixed moulds to minimise the number of skin pricks applied. In total, 11 separate skin tests were applied with standard techniques, with a histamine positive control. A positive response was one in which the skin test produced a wheal with flare that was 3 $\mathrm{mm}$ or more greater than that of the saline control.

Ten workers who did not live in the community were skin tested with the LCFA preparation. Nine had negative responses. The one positive result was in a person who spent part of a summer working with caddis flies.

MEASUREMENT OF CADDIS FLY-SPECIFIC IGE Serum caddis fly-specific IgE was measured by an indirect enzyme linked immunosorbent assay (ELISA) similar to an assay previously reported. ${ }^{5}$ For standardisation of the ELISA results between assays and estimation of the relative amount of caddis fly-specific $\operatorname{IgE}$ in each sample, a reference IgE serum obtained from a caddis fly allergic subject was defined as having $1000 \mathrm{U} / \mathrm{ml}$ of caddis fly specific IgE antibodies and used as a reference serum. Polystyrene immunoplates coated with caddis fly extract (made in our laboratory), after blocking free binding sites with $2 \%$ bovine serum albumin in phosphate buffered saline, were sequentially incubated with the test sample or the reference serum, rabbit antihuman IgE (Dakopatts, KD-2600 Glostrup, Denmark), enzyme conjugated goat antirabbit IgG (Jackson, ImmunoResearch Laboratories, West Grove, PA, USA), and substrate. The reaction was stopped by addition of $0.1 \mathrm{ml} 1$ $\mathrm{N} \mathrm{NaOH}$. Optical absorbance at $410 \mathrm{~nm}$ was read with a microplate reader. Values for caddis fly antibodies in unknown samples were calculated by interpolation from the dilution curve of the reference serum. A positive result was defined as $\geqslant 21 \mathrm{U} / \mathrm{ml}$, as this was the geometric mean $+2 \mathrm{SD}$ of 10 non-exposed people who did not work at the plant.

\section{PULMONARY FUNCTION TESTS}

Pulmonary function tests were performed with a Jones Pulmonaire waterless spirometer and Dynamite computer printer. The spirometer was calibrated before use each day of the survey. The reference values of Morris et al were used. 6 Spirometry was performed in a standing position without the use of nose plugs. The highest of three recordings as defined by the sum of the forced vital capacity (FVC) and forced expiratory volume in one second $\left(\mathrm{FEV}_{1}\right)$ were recorded. Also, the $\mathrm{FEV}_{1} / \mathrm{FVC}$ ratio, midmaximum expiratory flow rate (MMEF) and peak expiratory flow rate (PEF) were measured. Preshift testing was performed in the morning and postshift in the late afternoon.

A field diagnosis of occupational asthma was made for those workers who reported work related wheezing, breathlessness, or cough, were skin test positive to a caddis fly preparation, and had a greater than $12 \%$ fall in cross shift $\mathrm{FEV}_{1}$.

\section{STATISTICAL ANALYSIS}

Statistical analysis was performed with the $\mathrm{SAS}^{7}$ and Epi info ${ }^{8}$ computer programs. $\chi^{2}$ analysis was used for categorical data, supplemented by Fisher's exact two tailed test when appropriate to remove the effect of bias in the $\chi^{2}$ test due to the modest sample size. Analysis of covariance and paired comparison procedures were used to analyse preshift and postshift pulmonary function results and to control for the effect of smoking. A p value $<0.05$ was taken to indicate statistical significance.

Risk ratios were used as a measure of association between the rate of occurrence of events in exposed and unexposed groups. Those performing the skin tests, pulmonary function tests, and ELISA analysis were not aware of the workers' work area or results of the other tests.

\section{Results}

QUESTIONNAIRE

In total, 28 members of the workforce and management volunteered to enter the study representing $49 \%$ of the current workforce of about 57 employees. Two other persons who lived in the community also completed the protocol. 
Table 1 Characteristics of study participants

\begin{tabular}{lcll}
\hline & Work location 1 & Work location 2 & p Value \\
\hline No of participants & 18 & 10 & \\
\% of total employees & 53 & 43 & NS \\
Age (y; mean (SD) range) & $36 \cdot 4(12 \cdot 2)$ & $39 \cdot 9(8 \cdot 3)$ & NS \\
Sex (\% men) & $21-60$ & $22-49$ & $<0.003$ \\
Duration of employment (y) & 100 & 50 & NS \\
at plant (median (SD) range) & $3 \cdot 5(9 \cdot 3)$ & $3 \cdot 0(1 \cdot 8)$ & \\
Smoking state (\%) & $1-25$ & $2-7$ & NS \\
Current smoker & 24 & 50 & \\
Ex-smoker & 41 & 30 & \\
Never smoked & 35 & 20 & \\
\hline
\end{tabular}

As a worker's likelihood of coming into contact with caddis flies depended on the work location, subjects were divided into two groups based on their chance of exposure. Work location 1 refers to workers who worked in the control room or in other areas of the powerhouse excluding the office, the high exposed areas. Work location 2 refers to those that worked in the office and outside the powerhouse, and serves as a relatively unexposed control group. Also, as most members of the workforce lived in the community and community exposure could potentially lead to caddis fly sensitisation, their use as a control group identifies whether the sensitisation was occupationally or non-occupationally acquired. Although the use of a totally unexposed control group was considered, for reasons of time and expense it could not be pursued. The two members of the community who participated in the survey were not included in analyses of pulmonary function data and work related symptoms, but were included in analysis of general symptoms and skin prick responses. Table 1 summarises the demographic and employment information on the 28 workers. Workers in the work location 1 were more likely to be male.

Those who worked in work location 1 were more likely to complain of eye and nose symptoms, and breathlessness, than those working in work location 2 (table 2). None of these differences, however, were significant. When

Table 2 Association of symptoms and work location

\begin{tabular}{|c|c|c|c|c|c|}
\hline Symptom & $\begin{array}{l}\text { Work } \\
\text { location } 1\end{array}$ & $\begin{array}{l}\text { Work } \\
\text { location } 2\end{array}$ & $R R$ & $95 \% C I$ & p Value \\
\hline Number: & 18 & 10 & & & \\
\hline Eye & 15 & 6 & 1.39 & $0 \cdot 80-2 \cdot 40$ & NS \\
\hline Nose & 16 & 6 & 1.48 & $0 \cdot 87-2 \cdot 52$ & NS \\
\hline Sinus & 12 & 7 & 0.95 & $0.57-1.60$ & NS \\
\hline Wheeze & 15 & 8 & 1.04 & $0 \cdot 72-1 \cdot 51$ & NS \\
\hline Breathlessness & $12 \dagger$ & 4 & $1 \cdot 76$ & $0.78-4.00$ & NS \\
\hline Cough & 10 & 5 & $1 \cdot 11$ & $0.53-2.34$ & NS \\
\hline \multirow{2}{*}{\multicolumn{6}{|c|}{$\begin{array}{l}\text { Work-related } \\
\text { Symptom*: }\end{array}$}} \\
\hline & & & & & \\
\hline \multirow{9}{*}{$\begin{array}{l}\text { Number } \\
\text { Eye } \\
\text { Nose } \\
\text { Sinus } \\
\text { Wheeze } \\
\text { Breathlessness } \\
\text { Cough } \\
\text { Work related illness } \ddagger \\
\text { Average No of } \\
\text { work related } \\
\text { symptoms }\end{array}$} & 18 & 10 & & & \\
\hline & 13 & 2 & $3 \cdot 61$ & $1.01-12.89$ & 0.02 \\
\hline & 14 & 2 & 3.89 & $1 \cdot 10-13 \cdot 76$ & 0.005 \\
\hline & 9 & 4 & $1 \cdot 25$ & $0.51-3.04$ & NS \\
\hline & $11 \dagger$ & 3 & $2 \cdot 16$ & $0.78-5.92$ & $0 \cdot 12$ \\
\hline & $7 \dot{f}$ & $1+$ & $3 \cdot 71$ & $0.54-25 \cdot 62$ & NS \\
\hline & 99 & $0+$ & - & & 0.02 \\
\hline & 12 & 1 & $6 \cdot 67$ & $1.01-44.04$ & 0.006 \\
\hline & $3 \cdot 5$ & $1 \cdot 2$ & & & 0.01 \\
\hline
\end{tabular}

* Work related symptoms were defined as symptoms improving on weekends and vacations. †Missing value. $¥ A$ work related illness was defined as the presence of three or more work related symptoms. Work location 1 = control rooms and other areas of powerhouse excluding the office; Work location $2=$ office and outdoors. analysis was limited to work related symptoms, workers in work location 1 were more likely to complain of all the symptoms. Significant results were found for work related eye and nose symptoms and cough. For all symptoms the risk ratios were higher when the analysis was limited to work related symptoms compared with the presence of the symptom itself. The mean number of work related symptoms reported by workers in work location 1 was 3.5 whereas those in work location 2 reported 1.2 symptoms $(p=0.01)$.

A clinical diagnosis of a work related illness was defined by the presence of three or more work related symptoms. Twelve of the 18 workers in work location 1 fulfilled this definition compared with one of the 10 work location 2 workers $(p=0.006)$.

Three workers reported being diagnosed with asthma after beginning work at the plant. In two cases, asthma was diagnosed in the first year of employment and in one case after four years of work. Seven workers reported that their physician had diagnosed allergy to caddis flies.

\section{IMMUNOLOGICAL EVALUATION}

Twenty eight workers had skin tests to the battery of allergens. Two workers were not tested as they had recently taken an antihistamine medication that would influence interpretation of the results.

Eleven workers tested positive to both the CCFA and the LCFA. A further six tested positive only to the LCFA. No one tested negative to the LCFA and positive to the CCFA $(\mathrm{p}<0.001)$.

The average duration of employment at the plant for workers who had a positive reaction to the CCFA was 12.7 years. Those who were LCFA positive and CCFA negative averaged 2.0 years at the plant. The fact that no worker was CCFA positive and LCFA negative suggests a shorter sensitisation period for the LCFA. Those who were negative to both extracts worked on average 4.5 years at the plant. Most of these workers usually worked in areas where exposure to caddis flies was lower.

Fifteen of the 28 subjects tested positive to at least one allergen other than the two CFAs. Eleven tested positive to at least two other allergens. A positive skin reaction to the LCFA was associated with being atopic as defined by skin test positivity to at least one allergen mixture, excluding the CCFA ( $p<$ 0.008 ). If the definition of atopy was made more restrictive by the requirement of at least two positive skin tests, a positive association was still found $(p<0.016)$.

When CCFA was used in the analysis and one other skin test positivity was used as the definition of atopy (excluding the LCFA), a significant association was still found $(p=$ 0.043 ). If positive reactions to two antigen mixtures was used, the association bordered on significance $(p=0.055)$.

Table 3 compares the symptom and work related symptom frequency for study participants according to sensitivity to caddis fly 
Table 3 Association of symptoms and caddis fly skin test response

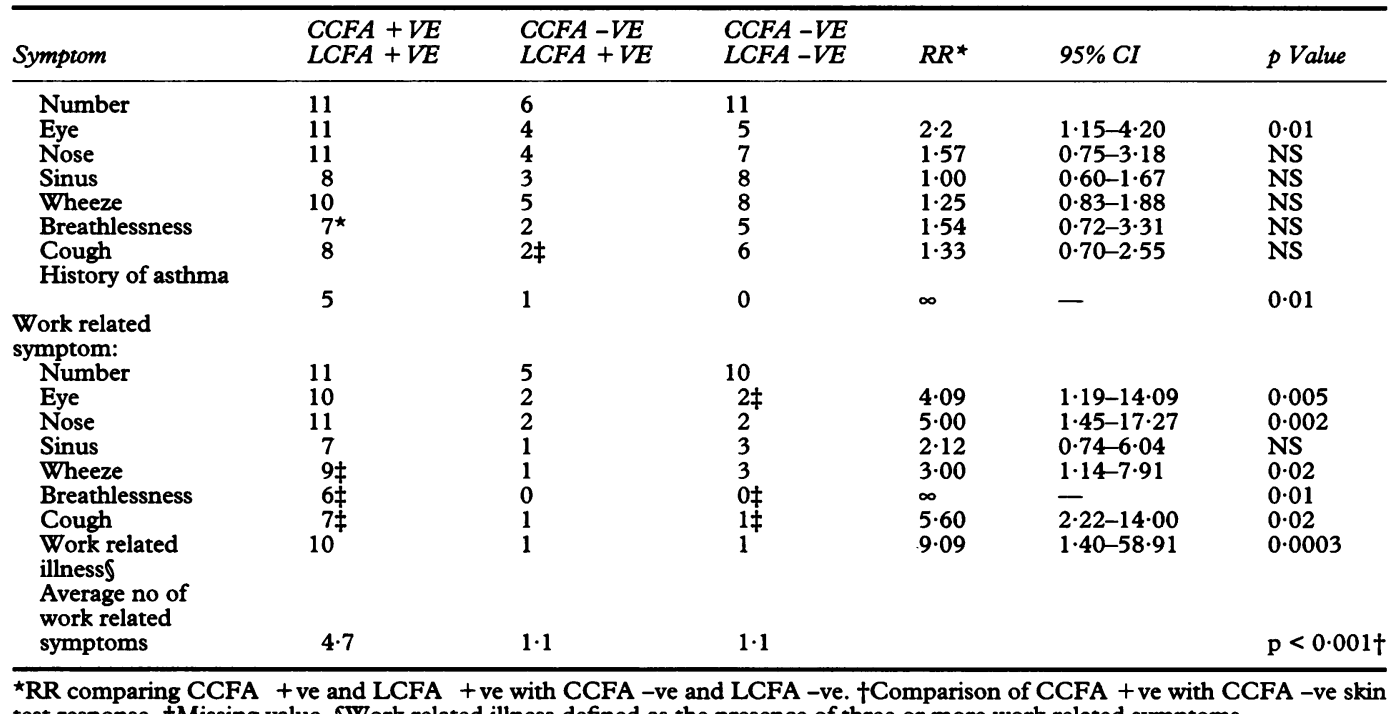

test response. $¥$ Missing value. WWork related illness defined as the presence of three or more work related symptoms

antigen. All associations between symptoms and a positive reaction to the caddis fly antigens were higher for work related symptoms than for symptoms in general. Significant associations were found for five of the six symptoms studied and caddis fly antigen positivity. A history of asthma was also associated with CCFA positivity. Analysis according to sensitivity to LCFA was similar to that of sensitivity to CCFA and is not presented.

Ten of the 11 workers who were CCFA positive reported three or more work related symptoms, fulfilling the definition of a work related illness. Those who were CCFA positive were more likely to have a work related illness than CCFA and LCFA negative workers $(p=0.0003)$. Although a larger percentage who were LCFA positive and CCFA negative reported certain work related symptoms compared with those who were negative to both caddis fly antigens, the differences were not significant.

Twenty nine persons had blood taken for an IgE-ELISA against caddis flies. Table 4

Table 4 Comparisons of immunological testing for caddis fly (CF) sensitivity

\begin{tabular}{lllll}
\hline IgE ELISA & $C C F A+V E$ & $C C F A-V E$ & $C C F A-V E$ & \\
Result & $L C F A+V E$ & $L C F A+V E$ & $L C F A-V E$ & Total \\
\hline Positive & 10 & 3 & 1 & 14 \\
Negative & 1 & 3 & 9 & 13 \\
\hline
\end{tabular}

$\mathrm{p}<0.0001$.

Table 5 Sensitivity and specificity of immunological testing in identifying workers who reported three or more work related symptoms

\begin{tabular}{|c|c|c|c|c|}
\hline Test & Sensitivity & Specificity & $\begin{array}{l}\text { +ve } \\
\text { Predictive } \\
\text { value }\end{array}$ & $\begin{array}{l}\text { - ve } \\
\text { Predictive } \\
\text { value }\end{array}$ \\
\hline $\begin{array}{l}\text { Commercial caddis } \\
\text { fly antigen }\end{array}$ & $83 \cdot 3 \%(10 / 12)$ & $92.9 \%(13 / 14)$ & $90 \cdot 0 \%(10 / 11)$ & $86 \cdot 7 \%(13 / 15)$ \\
\hline Laboratory caddis & $91 \cdot 7 \%(11 / 12)$ & $64 \cdot 3 \%(9 / 14)$ & $68 \cdot 8 \%(11 / 16)$ & $90.0 \%(9 / 10)$ \\
\hline $\begin{array}{l}\text { ny andgen } \\
\text { Caddis fly IgE - } \\
\text { ELISA }\end{array}$ & $69 \cdot 2 \%(9 / 13)$ & $71 \cdot 4 \%(10 / 14)$ & $69 \cdot 2 \%(9 / 13)$ & $71.4 \%(10 / 14)$ \\
\hline $\begin{array}{l}\text { All three tests } \\
\text { positive }\end{array}$ & $75.0 \%(9 / 12)$ & $92 \cdot 3 \%(12 / 13)$ & $90.0 \%(9 / 10)$ & $80.0 \%(12 / 15)$ \\
\hline
\end{tabular}

compares the results of the ELISA test and the two caddis fly antigen skin tests. There was a strong association between the caddis fly skin test and ELISA results.

Analysis was performed to see whether work location was associated with immunological test results. Workers were 3.7 times as likely to have a positive response to the LCFA if they worked in work location 1 than if they did not $(p=0.009)$. Workers were 5.3 times as likely to have a positive response to the CCFA if they worked in location $1(p=$ $0.036)$. The association between the IgE ELISA response and work location, although positive, was not significant.

In total, $13(46 \%)$ workers met the definition of a work related illness. Table 5 shows the sensitivity and specificity of the various immunological tests in detecting these people. The CCFA had the highest positive predictive value of the three tests.

PULMONARY FUNCTION TESTS

All pulmonary function test results were standardised to \% predicted values to control for variation in height, age, and sex. Table 6 compares the workers' results according to sensitivity to CCFA. Results were similar when analysis was performed with LCFA. Although no significant differences were found between the two groups, those who tested positive to the CCFA had consistently lower overall results than those who tested negative. Controlling for the effects of cigarette smoking did not alter these results.

Postshift pulmonary function testing was performed on 20 people. Interpretation of the postshift tests is limited because the testing was performed during the hottest days of the summer when temperatures in the powerhouse were reported to exceed $42^{\circ} \mathrm{C}$. Thus it is certain that some workers were not doing their usual work during the test period. One worker (CCFA positive) had a $20 \%$ cross shift fall in $\mathrm{FEV}_{1}$. Overall, there was a significant decrease in FVC of $3.4 \%$ predicted. The 
Table 6 Pulmonary function test results according to presence or absence of commercial caddis fly skin test response*

\begin{tabular}{|c|c|c|}
\hline & $C C F A-V E$ & $C C F A+V E$ \\
\hline \multicolumn{3}{|l|}{ Preshift } \\
\hline Number & 15 & 11 \\
\hline FVC & $102 \cdot 81$ & $97 \cdot 6$ \\
\hline FEV $_{1}$ & $99 \cdot 9$ & $91 \cdot 6$ \\
\hline $\mathrm{FEV}_{1} / \mathrm{FVC}$ & $98 \cdot 3$ & 95.6 \\
\hline MMEF & $82 \cdot 4$ & 73.0 \\
\hline PEF & $82 \cdot 6$ & $76 \cdot 9$ \\
\hline \multicolumn{3}{|c|}{$\begin{array}{l}\text { Postshift - } \\
\text { preshift change } \\
\text { in } \% \text { predicted: }\end{array}$} \\
\hline Number & 12 & 8 \\
\hline FVC & $-0.7(0.07)$ & $-3.4(0.02)$ \\
\hline $\mathrm{FEV}_{1}$ & -0.6 (NS) & $-5 \cdot 4(0 \cdot 12)$ \\
\hline FEV, FVC & +0.6 (NS) & $-3 \cdot 1$ (NS) \\
\hline MMEF & $-1 \cdot 0$ (NS) & -7.0 (NS) \\
\hline PEF & $-2 \cdot 5$ (NS) & -2.9 (NS) \\
\hline
\end{tabular}

* No significant differences were found between the groups in any of the tests either before or after controlling for the effect of cigarette smoking. tp Values in parentheses.

decrease found of $5.4 \%$ predicted in $\mathrm{FEV}_{1}$ was not significant (table 6).

Further analysis (table 7) compared those who usually worked in location 1 with those working in location 2 while controlling for the effects of cigarette smoking. For consistency, the two subjects who were not skin tested were not included in this analysis, although their inclusion did not significantly alter the results. Workers in work location 1 were found to have lower $\mathrm{FEV}_{1}, \mathrm{FEV}_{1} / \mathrm{FVC}$, and MMEF compared with those in work location 2. Although those working in work location 1 had generally slightly larger cross shift decrements in pulmonary function test results, none of the differences were significant.

\section{Discussion}

The level of symptoms reported by survey respondents was high. Work related symptoms were reported more often by workers in work location 1 . Ten (91\%) of those who were CCFA positive reported three or more work related symptoms. This test had the highest positive predictive value of the immunological tests studied, in identifying those who had a work related illness. The LCFA, although slightly more sensitive, was

Table 7 Pulmonary function test results according to work location *

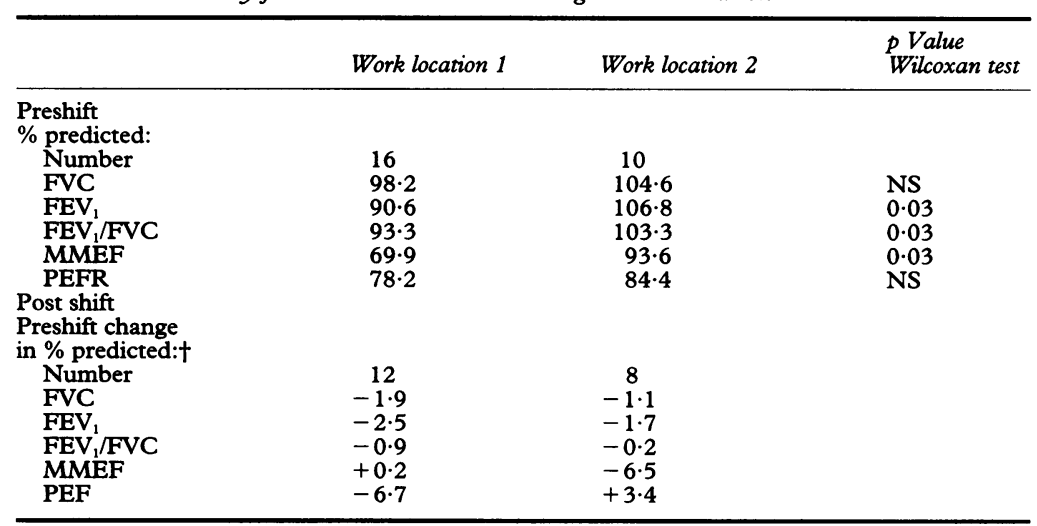

$\star$ Results were not different when controlled for cigarette smoking. $†$ No significant preshift and postshift differences were detected. less specific in identifying these workers. This may be due to the fact that this antigen was more concentrated and would identify workers whose sensitivity was not clinically important. Atopic workers, as determined by skin test positivity to common antigens, were more likely to test positive to the caddis fly antigens.

Significant differences in pulmonary function test results were found according to work location, but not sensitivity to CCFA. The differences in baseline pulmonary function test results in the workers in work location 1 may be due to the fact that subjects working in work location 1 had slightly lower than expected values, and the control group, those working in work location 2 , slightly higher than expected values. Sensitivity to CCFA was not an important predictor of any baseline pulmonary function test result when entered into a regression model with work location. The differences in pulmonary function test results according to work location are therefore unlikely to be due to caddis fly sensitisation.

Differentiation of workers according to sensitivity to CCFA produced greater cross shift change in FVC, $\mathrm{FEV}_{1}, \mathrm{FEV}_{1} / \mathrm{FVC}$ ratio, and MMEF than classification by work location. These findings are consistent with the hypothesis that occupational exposure to caddis flies in sensitised subjects could lead to reversible changes in airway function. The lack of statistical significance may be due to the small size of the study.

One worker met our field definition of occupational asthma. Had we been able to use serial peak flow measurements or specific bronchial challenges it is possible that we would have identified more cases of occupational asthma induced by caddis flies.

The major limitation of this study is the small number of participants. Therefore, in some circumstances, trends were found that did not attain significance. If the size of the effects found in the sample are accurate, however, the results would be of clinical significance.

A second limitation is that only $49 \%$ of the workforce participated in the survey. The reason for non-participation is not known for most of the workers. During the survey some non-participants stated that they did not want to participate as they had no symptoms. Alternatively, some non-participants may have been concerned that identification of allergy to caddis flies may have affected their employment, even though they were assured that all results were confidential. One nonparticipant likely did have occupational caddis fly allergy. He was examined before the survey by one of us (AK), reported a new onset of asthma since beginning work at the facility, had significant work related symptoms, and was CCFA positive. Even if it is assumed that all of the non-participants were not sensitised, a sizable proportion of the workforce $(19 \%)$ would still be CCFA positive.

A third potential limitation is that those who worked in work location 2 were predominately management and secretarial staff, 
which would make them different from the predominantly male workforce in work location 1. Although these differences could affect the results in some types of investigations, skin prick testing is not influenced by socioeconomic or sex differences. Further, analysis of the pulmonary function data was standardised to $\%$ predicted to control for age, height, and sex.

A further limitation in cross sectional studies such as this, is that the study population involved an active workforce. Former employees or those off sick did not participate. For this reason those who developed severe allergic symptoms after exposure to caddis flies and left employment could not be evaluated. This selection bias tends to minimise the prevalence of problems after exposure to caddis flies as some of the most sensitive workers are not evaluated.

\section{Conclusions}

Workers employed in areas thought to be more heavily exposed to caddis flies had more work related symptoms consistent with allergy to caddis flies and were more likely to have evidence of skin test reactivity to caddis fly antigens. The skin response to the CCFA was, of the three immunological tests used, the best predictor of workers having three or more work related symptoms. Occupational exposure to caddis flies proved to be a significant health problem at this worksite.

1 Parlato SJ. The case of coryza asthma due to sandflies (caddis flies). $\mathcal{F}$ Allergy 1929;1:35-42.

2 Kino T, Junichi C, Kouji F, et al. Allergy to insects in Japan. III High frequency of IgE antibody responses to insects (moth, butterfly, caddis fly, and chironomid) in patients with bronchial asthma and immunochemical patients with bronchial asthma and immunochemical responses quantitative of the insect-related airborne par-
ticles smaller than $10 \mu \mathrm{m}$ in diameter. $f$ Allergy Clin Immunol 1987;79:857-66.

3 Kagen SL, Yunginger JW, Wynn SR. Occupational respiratory allergy due to caddis fly aeroallergens (abstract). $\mathcal{F}$ Allergy Clin Immunol 1986;77:168.

4 Ferris EG. Epidemiology standardization product. Am Rev Respir Dis 1979;118(suppl): 1-120.

5 Peng Z, Simons FER, Becker AB. Measurements of ragweed-specific IgE in canine serum by use of enzymelinked immunosorbent assays, containing polyclonal and monoclonal antibodies. Am F Vet Res 1993;54:239.

6 Morris JF, Koshki A, Johnson LC. Spirometric standards for healthy nonsmoking adults. Am Rev Respir Dis 1971; 103:57-67.

7 SAS Institute SAS procedure guide. Version 6.07. Cary North Carolina: SAS Institute, 1986.

8 Dean AD, Dean JA, Burton AH, et al. Epi Info, version 5: a work processing, data base, and statistics program for epidemiology and microcomputers. Stony Mountain Georgia: USD Incorporated, 1990.

\section{Correspondence and editorials}

Occupational and Environmental Medicine welcomes correspondence relating to any of the material appearing in the journal. Results from preliminary or small scale studies may also be published in the correspondence column if this seems appropriate. Letters should be not more than 500 words in length and contain a minimum of references. Tables and figures should be kept to an absolute minimum. Letters are accepted on the understanding that they may be subject to editorial revision and shortening.

The journal also publishes editorials which are normally specially commissioned. The Editor welcomes suggestions regarding suitable topics; those wishing to submit an editorial, however, should do so only after discussion with the Editor. 